\title{
Nanoherbals in Human Healthcare: A Proposed Research and Development Roadmap I
}

\author{
S. AHMAD* AND U. HASHIM \\ Institute of Nano Electronic Engineering, \\ University of Malaysia Perlis, Kangar, Perlis, Malaysia
}

\begin{abstract}
Bioactive secondary metabolites derived from herbs are examined for their suitability of conversion into nanoforms having flexible morphological controls, surface stabilizations and surface functionalization. This can lead to stable chemical conjugations based on molecular recognition for their possible applications in the form of smart pharmaceuticals, nutraceuticals, cosmaceuticals and many other related areas of human healthcare using green chemistry routes. Using the principles of nanoscience and technology in association with genomics and proteomics, an attempt has been made to decipher whether a suitable form of drug discovery and targeted drug delivery like schemes are feasible in case of such nano phytochemicals using various kinds of nanosize carriers and labelling molecules already identified in the course of investigations of contemporary single molecule drug developments. Additional efforts can clarify whether such species will be successful in the early detection of diseases based on marker molecules. Once identified, these green phytochemicals will certainly replace many hazardous chemical compounds by their environmentally friendly and sustainable forms in times to come.
\end{abstract}

Key words: Secondary metabolites; nanoherbals; drug discovery; drug delivery; phytochemicals; nutraceuticals; cosmaceuticals; genomics; proteomics; bioassays; screening

Medicines required for treating, preventing and alleviating disease symptoms constitute a major component in human healthcare system, notably mental and physical well being. Contemporary or molecular medicines can apply the findings of biomedical science research and technologies to diagnose and treat diseases through medication, surgery and other therapy. There are two types of therapies commonly used, namely traditional and contemporary system of medicine. Traditional medicine (TM) may involve a combination of systems like Indian (Ayurveda), Chinese and Arabic (Unani) medicines in addition to a variety of indigenous medicines evolved locally. TM includes both medication and non-medication based therapies. Medication therapies employ herbal medicines, animal parts and/or minerals whereas non-medication type may include acupuncture, manual and spiritual therapies. In those countries where the major healthcare system uses allopathic medicines or where TM is not a part of National Healthcare System, it is often termed as 'complementary', 'alternative' or 'non-conventional' medicine. Herbs in TM are employed in the form of their various parts or extracts including leaves, bark, berries, roots, gums, seeds, stems and flowers that have nourishing and healing properties.

Herbs have been used for human healthcare throughout human history. However, contemporary medicines in modern times belong to a broad class of physical, chemical,

* Corresponding author (e-mail: drsahmad@email.com) 
biological and medical techniques that are used to describe molecular structures and mechanisms, identify fundamental molecular and genetic changes caused due to disease and develop molecular interventions to correct such anomalies. Molecular medicines, thus, employ cellular and molecular level descriptions to focus on interventions rather than holistic treatment of the patient.

Molecular medicines have succeeded well in treating large number of diseases primarily due to a better understanding of biochemical processes causing molecular level interactions in human physiology. In contrast, the present status of herbal medicines does not enjoy such support from rigorous animal and human experiments correlating each bioactive compound with specific therapeutic effects. It is known that herbs are quite effective in curing several chronic diseases. However, their precise identification is a common problem out of so many similar ones, but having different types of constituents. Systematic studies are necessary to establish their identities more precisely.

Standardization of herbal ingredients is another issue concerning the use of herbs as a dietary supplement, nutraceutical and cosmetics purposes. Geographical and environmental conditions prevailing during plantation cause large variations in bioactive constituents. These efforts need quantitative standardization for ensuring efficacy. These complexities could possibly be simplified provided therapeutic influences of each constituent was known individually and in synergy with others. Further complications add to changes occurring during their pre- and post-processing stages that may, however, become crucial in modifying bioactive compounds. In order to have the herbal preparations in reproducible form by understanding and resolving various issues, it is worthwhile to use the concepts of nanoscience and technology along with those of genomics and proteomics to resolve connected problems.
Applications of nanoscience and technology in molecular medicine are fast emerging as a new discipline of nanomedicine involving diagnosing, treating and preventing diseases and injuries, relieving pain and preserving and improving human health using molecular tools and knowledge of human physiology. It is very important to note that the materials having at least one dimension in the nanoscale exhibit significantly improved physical, chemical and biological properties due to the quantum size effect. The important contribution of nanoscience is currently being assessed extensively to convert molecular medicine into nanomedicine and target deliveries where the drug molecules are transported through nanosize carriers to the actual disease site, with the help of conjugated targeting and marker molecules. Targeted delivery of molecular medicines is currently under extensive development with reference to dose reductions, enhanced efficacies and reduced side effects.

After having observed therapeutic properties of herbal medicines in treating even incurable ailments over several thousands of years in past, it is natural to ask whether it is possible to convert them into nanoforms. In case yes, then could they possibly be considered for their targeted deliveries aiming for similar advantages as established in case of molecular medicines? An attempt has been made in this study to search for possible answers to these questions after examining various technological aspects of herbal medicines. In this quest, it is necessary to review the existing processes of nanoform conversion, surface functionalization for morphological stabilization and chemical conjugations with imaging and drug molecules/ entities. The final conversion deliveries involves the extract of single or multiple species and their active phytochemicals. Subsequently, suggestions are made for drawing a systematic plan of action for conducting future R\&D. The various results reported are concerning the delivery of molecular nanomedicines have excessively been referred to while establishing 
similar methodologies that are appropriate to the development of herbal medicine.

Rain forests of Malaysia and the adjoining regions offer valuable resources for nanoherbals development. Malaysia has around 12,000 species of flowering plants, of which $10 \%$ are medicinals and only a fraction of which has been screened for medicinal uses, and confined mainly to alkaloids. Systematic bioassays-based investigations remain to be carried out. Existing diverse biochemical activities of Malaysian herbs suggest valuable bioactive properties. Modifications of nanoherbals comprising a large variety of phytochemicals and traditional knowledge will be helpful in the assessment of the molecular nanomedicines.

The assessment of herbal phytochemicals for therapeutic properties of human ailments, include compounds that are appropriate for food, nutrition and cosmetic applications. Inclusion of these is advantagous as nanoformulations in food supplements, nutraceuticals and cosmetics.

\section{HERBAL NANOFORMULATIONS}

Organic, inorganic and biological nanoparticles can be prepared by a number of methods involving physical vapour deposition, colloidal solution, mechanical alloying, milling, chemical vapour deposition, sol-gel, mechanical grinding, hydrothermal, supercritical fluid, biomimetic, flame pyrolysis, laser ablation, ultrasonic, electro deposition and explosion, plasma synthesis, microwaves and precipitation techniques. Of these techniques milling, solgel, chemical vapour deposition and colloidal chemistry-based methods. For nanoparticles the control of shape and size by using proper surfactant, capping agents, template and selfassembly processes are important. Further development of appropriate types of surface modification techniques has rendered these nanoparticles completely dispersed in a given medium.
Self-aggregation is common in nanoparticles during storage. This may cause serious problems in therapeutic and other applications. Understanding the mechanism of self-aggregation and its prevention could be applied elsewhere as well. For example, in a number of central nervous system related diseases, protein-protein aggregation is the main cause. It is quite likely that any method developed for controlling nanoparticles aggregation may be helpful.

For extracting useful phytochemicals from the natural herbs and plants supercritical fluid extraction (SFE) using $\mathrm{CO}_{2}$ is currently being explored as an alternative to solvents (Hartono et al. 2001). Supercritical $\mathrm{CO}_{2}$ is selective in separating specific compounds without leaving unwanted residues in the extracts and is also free from the risk of thermal degradation of processed bioactive compounds due to mild temperature involved. Supercritical fluids having enhanced solvating power are highly sensitive to small changes in temperature, pressure and modification of the solvent consisting of entrainers and provide solvent-free extracts. Transport properties of supercritical fluids facilitate deeper penetration in the plant matrix and more efficient and faster extraction than with normal organic solvents.

SFE is carried out in high-pressure vessels made of materials capable of standing elevated pressure and temperature while configured in batch or continuous mode. In this process, the supercritical solvent is thoroughly mixed and allowed to stay for a while with the substance from which some specific bioactive constituent is to be extracted. The supercritical solvent saturated is allowed to reach atmospheric pressure leading to separation of the solubilised product that in turn is taken out from the separation chamber and recycle the solvent for further use. By controlling the process parameters nanosize precipitates are formed on a large scale (Hakuta et al. 2003). Supercritical fluid technology is also being increasingly 
employed as an analytical technique for qualitative and quantitative identifications of bioactive constituents of natural products that are specifically heat sensitive (Dionisi et al. 1999; de Castro \& Jimenez-Carmona 2000).

It has been possible to use SFE for extraction and fractionation of bioactive compounds from edible oils and fats; purification of solid matrices; separation of tocopherols and other antioxidants; clean-up of herbal medicines and food products from pesticides; detoxification of shellfish and concentration of fermentation broth, fruit juices and many others (Eggers et al. 2000; Lang \& Wai 2001).

A large variety of alkaloids such as caffeine, morphine, emetine and pilocarpine are used in numerous medicinal products. The recovery of such alkaloids from natural herbs is important for food, pharmaceutical and cosmetic industries. For example, SFE is found to be selective indecaffeination of coffee and black tea. Recent studies have demonstrated the potential use of solvent and anti-solvent properties of $\mathrm{CO}_{2}$ in the recovery of alkaloids like theophylline, theobromine and pilocarpine and many others (Saldaña et al. 2002). Similarly, cholesterol removal from meat, eggs and dairy products has been very effective using SFE process involving $\mathrm{CO}_{2}$ alone or combined with ethane and propane as co-solvent (Greenwald 1991). Supercritical $\mathrm{H}_{2} \mathrm{O}$ oxidation has been developed for safer destruction of toxic organic materials as a viable alternative to conventional incineration and land disposal.

Rapid expansion of supercritical solutions through very small size nozzles is currently being used for the formation of submicron size nanopowders appropriate for the formulation of drug particles, drug containing polymeric particles and solute containing liposomes (Jung \& Perrut 2001, Kompellla \& Koushik 2001). The supercritical anti-solvent precipitation technique is useful in the production of micron and submicron size particles with controlled particle shape, size and size distribution (Jung $\&$ Perrut 2001). Though morphologies included various kinds of shapes like spheres, rod-like and snowballs but commonly encountered ones are spherical particles. SFE is used for protein purification using fractional precipitation of protein alkaline phosphatase, insulin, lysozyme, ribonuclease, trypsin and their mixtures from dimethylsulphoxide (Reverchon et al. 2000).

Some of the typical extraction parameters (pressure, temperature used and percentage recoveries achieved) optimized experimentally is summarized in support of superior performance of SFE for production of different kinds of bioactive substances (Shi et al. 2007).

Avocade seed oil (75.8 MP, $\left.70^{\circ} \mathrm{C}, 58.2 \%\right)$; paprika (55.2 $\left.\mathrm{MP}, 50^{\circ} \mathrm{C}, 7.2 \%\right)$; rice bran $(65.5$ $\left.\mathrm{MP}, 70^{\circ} \mathrm{C}, 19.2 \%\right)$; soybean $\left(55.2 \mathrm{MP}, 50^{\circ} \mathrm{C}\right.$, $19.4 \%)$; wheat bran $\left(55.2 \mathrm{MP}, 50^{\circ} \mathrm{C}, 4 \%\right)$; sunflower oil (32-35 MP, $40-50^{\circ} \mathrm{C}, 36 \%$ ); corn germ oil $\left(55.2 \mathrm{MP}, 50^{\circ} \mathrm{C}, 50 \%\right)$; wheat germ oil (13-41 MP, $35-50^{\circ} \mathrm{C}, 98.7 \%$ ); canola oil (41-62 MP, $45-70^{\circ} \mathrm{C}, 44 \%$ ); carotene lutein (30-70 MP, $40^{\circ} \mathrm{C}, 90 \%$ ); cardamom oil (10 MP, $\left.40^{\circ} \mathrm{C}, 85 \%-95 \%\right)$; phospholipids (68.2 MP, $\left.80^{\circ} \mathrm{C}\right)$; carotene $\left(20.7 \mathrm{MP}, 55^{\circ} \mathrm{C}\right)$; black pepper - piperine (9-15 MP, $\left.40^{\circ} \mathrm{C}, 18 \%\right)$; ginger gingeroles ( $30 \mathrm{MP}, 40^{\circ} \mathrm{C}, 8.4 \%$ ); palm oil cartenoid (20-30 MP, $\left.45-55^{\circ} \mathrm{C}, 7 \%\right)$; tomato lycopene (17-28 MP, $\left.40-80{ }^{\circ} \mathrm{C}\right)$; peppermint/ spearmint - menthol $\left(6-18 \mathrm{MP}, 24-43^{\circ} \mathrm{C}, 76 \%\right)$; chilli oil (30 MP, $\left.40^{\circ} \mathrm{C}\right)$; coriander oil (15 MP, $50^{\circ} \mathrm{C}$; $\left.0.61 \%\right)$; thai sweet tamrind antioxidant $\left(10-30 \mathrm{MP}, 35^{\circ}-80^{\circ} \mathrm{C}\right)$ and fish oil $(15 \mathrm{MP}$, $\left.50^{\circ} \mathrm{C}\right)$.

Most of the phytochemicals from the plants are not water soluble because of the absence of ionic bonds, but are easily soluble in organic solvents like alcohols, hexanes, dioxanes, acids, ethers, methylene chloride, trichloroethylene and acitonitrile. Sequential extractions using a number of organic solvents in specific order are generally employed in their extractions. Plant materials are ground, shredded, chopped, 
pulverized, compacted or macerated to allow the solvents to properly penetrate inside the mass. However, the pressurized low polarity water extraction method has been developed as another variant to reduce the cost of organic solvents. For example a subcritical state of water is achieved by heating it to $374^{\circ} \mathrm{C}$ at $22.1 \mathrm{MP}$ for reducing the associated viscosity, surface tension, polarity and dissociation constant and thus making it similar to a number of organic solvents. Using this kind of subcritical water is another alternative to hydrodistillation (Cacace \& Mazza 2007) having significant benefits in terms of higher selectivity, better cleanliness, speed and cost reduction as compared to other extraction processes including SFE. Some of the examples using subcritical water extraction process are listed here. These are: clove oil $\left(125^{\circ} \mathrm{C}-250^{\circ} \mathrm{C}, 2.4 \mathrm{MP}-17 \mathrm{MP}\right)$; fennel oil $\left(50^{\circ} \mathrm{C}-200^{\circ} \mathrm{C}, 2 \mathrm{MP}\right)$; peppermint fragrance $\left(50^{\circ} \mathrm{C}-200^{\circ} \mathrm{C}, 6 \mathrm{MP}\right)$; raspberry, bilberry, chokeberry $\left(110^{\circ} \mathrm{C}-160^{\circ} \mathrm{C}\right)$ and whole flaxseed $\left(100^{\circ} \mathrm{C}-160^{\circ} \mathrm{C}, 5 \mathrm{MP}\right)$.

\section{HERBALS IN HUMAN HEALTHCARE}

Several plant species have been in use as medicines, sources of food and nutrition, flavouring agents, spices and cosmetics since long. Different plant parts like roots, stems, branches, leaves, flowers, fruits and seeds as extracts, powder or coarse mixtures are frequently involved. The herbs are relatively more effective and safer than synthetic molecules employed in the form of molecular medicines. Detailed studies are being pursued on phytochemicals present in such plants and their influence on human physiology. Characteristic features of these herbs include antioxidants, anti-inflammatory, antimicrobial, antidepressant, sedative, antiallergic and many other properties. Some of the findings published are briefly discussed below.

\section{Herbal Pharmaceuticals}

Pharmaceuticals are the substances for curing, preventing, or recognizing diseases and relieving pains through their applications. Using herbs to treat disease has been very common among the non-industrialized societies of the world. A number of traditions have dominated the practice of herbal medicines; and include - the 'classical' herbal medicine system based on Greek and Roman sources; Siddha and Ayurvedic medicine systems from India, Chinese herbal medicine and Unani-Tibb medicine of Graeko-Arab origin. Many of the currently used contemporary pharmaceuticals have been long known in form of herbal remedies, and include opium, aspirin, digitalis and quinine to name a few. The World Health Organization (WHO) has estimated that $80 \%$ of the world's population presently uses herbal medicine as a part of primary health care. In comparison to the expensive molecular medicines, herbal medicines are grown from seed or gathered from nature as low cost alternative.

Three vital aspects of herbal medicine research namely phytochemistry; pharmacognosy and horticulture are currently being pursued. In phytochemistry, herbs are characterized for their bioactive compounds that are fractionated and analyzed structurally. Pharmacognosy involves their bioactivity assays, identification of action modes and related target sites. In addition to these mentioned analytical investigations, horticultural studies aim for optimal plant growth techniques that are most appropriate for their cultivations. This has special significance as many of the medicinal plants are harvested in the wild and conditions for their cultivation are still very poorly understood. Random cultivations of the medicinal plants lead to wide variations in the plant qualities, resulting in improper choice of raw materials for herbal medicines. Concerning plant physiology, extensive scope exists for basic research on medicinal herbs and phytochemicals.

Medicinal plants contain primary and secondary metabolites. The primary metabolites 
are carbohydrates, lipids, proteins, heme, chlorophyll and nucleic acids and responsible for building and maintaining plant cells (Wink $\&$ Schimmer 1999). Secondary metabolites are generally plant specific as they are not involved in common plant metabolism as such but provide defense capabilities against damages caused by plant eating animals, pathogens, inter-plant competition besides facilitating the process of pollination (Wink \& Schimmer 1999). They also provide resistance against environmental stresses arising due to change in temperature, water availability, light/UV exposure and mineral nutrients. Recent studies have shown that secondary metabolites provide plant growth regulation, modulation of gene expression and signal transduction. Some of them that provide cytotoxicity against pathogens. Similarly, those having defenses against damage are effective as anti-depressant, sedative, muscle relaxant and anesthetic due to their interactions with the central nervous system. Typical characteristics of these metabolites are the result of ecological evolution through interactions with molecular targets influencing cells, tissues and physiological functions in competing with micro-organisms, plants, and animals (Wink \& Schimmer 1999). Some of them resemble endogenous metabolites, ligands, hormones, signal transduction molecules, or neurotransmitters and have medicinal effects due to their potential target sites in central nervous and endocrine systems.

Contrary to the single chemical synthetic pharmaceuticals, many phytochemicals cause synergistic actions involving several other chemical compounds acting at single or multiple target sites associated with a physiological process. This could possibly be put to use in eliminating side effects associated with the use of a single compound. Multiple chemicals acting in synergy has its origin in the functional role of secondary metabolites in promoting plant survival. For example, the role of secondary metabolites as defense chemicals affecting multiple target sites would reduce the chances of these organisms developing resistance (Wink \& Schimmer 1999).

Some examples of medicinal herbs are cited that have been considered for their therapeutic applications even in the USA, Europe and elsewhere. This includes Ginseng, St John's Wort, Gingko Biloba, Kava and Echinacea $s p$., and their medicinal properties have been recently reviewed (Briskin 2000).

Ginseng is a de-stressing tonic that raises the physical and mental capabilities (Schulz et al. 1998), showing immuno-stimulatory effect in humans (Schulz et al. 1998; WHO 1999; Blumenthal et al. 2000). The large number of triterpene saponins, collectively called ginsenosides (Huang 1999) are responsible for its medicinal properties. Experimental studies indicate that they involve the hypothalamuspituitary-adrenal axis by influencing serum levels of adrenocorticotropic hormone and corticosterone (Huang 1999).

St. John's Wort is currently very popular for treating depression (Schulz et al. 1998). The aerial portion of the plant is harvested after flowering and then used for preparing alcohol/ aqueous extract (Schulz et al. 1998; Blumenthal et al. 2000). Hypericin and pseudohypericin are predominant components and is standardized according to hypericin content (Schulz et al. 1998). Napthodianthrones in St. John's Wort is influenced by environmental factors such as light and mineral nutrients. Hypericin and pseudohypericin contribute towards the antidepressant action.

Ginkgo has been in use for thousands of years in Chinese medicine (Huang 1999). Modern formulations use acetone extract of the leaves instead of seeds (Schulz et al. 1998). Clinical studies show that Ginkgo improves peripheral and cerebrovascular circulation (Schulz et al. 1998; Huang 1999; Blumenthal et al. 2000). Ginkgo is also effective in 
improving cognitive decline due to vascular insufficiency dementia in elderly patients (Schulz et al. 1998; Blumenthal et al. 2000) besides its use in tinnitus, vertigo and improving circulation in the legs (Schulz et al. 1998).

Kava is known for treating anxiety, nervous tension, agitation and insomnia patients. Clinical studies have revealed its sedative properties to be comparable to that of benzodiazapines but with no physical or psychological dependence (Singh \& Blumenthal 1997; Schulz et al. 1998). The medicinal properties of Kava are attributed to styrylpyrones that influence several neurotransmitter systems including those involving Gln, GABA, dopamine, and serotonin (Schulz et al. 1998). Recent studies show that kavapyrone present in roots are influenced by environmental factors e.g. it increases with irrigation and mineral nutrient supplements and decreases with shading (Lebot et al. 1999).

Various parts of Echinacea purpurea are used for wound healing, infection and rattle snake bites (World Health Organization 1999; Blumenthal et al. 2000). Current interest lies in using this plant for colds, flu-like and respiratory infections (Schulz et al. 1998; WHO, 1999). Echinacea extracts modulate the immune system including stimulation of phagocytic activity of lymphocytes, fibroblasts for new tissue production, increased respiration and elevated leukocytes mobility (Schulz et al. 1998; WHO, 1999). Echinacea extract is effective in inhibiting tissues and bacterial hyaluronidase and is found active in infections and preventing spread to other body parts (WHO 1999).

\section{Nutraceuticals}

Various food ingredients have strong links with human health and their deficiencies cause various diseases (Ali et al. 2009). The protective effects of flax oil tocotrienols, turmeric curcuminoids, carrot carotenoids, vegetable and fruit flavonoids, fatty acids in sea foods, garlic allyl sulfides and mushroom/cereal glucans are a few examples of nutraceuticals. Certain ingredients of saturated fats e.g. sphingolipids, conjugated linolenic acid and monounsaturated fatty acids are effective in controlling carcinogenesis, immunomodulation and lipid profile respectively (Ali et al. 2009). Nuts lower cholesterol because of the proper ratio of polyunsaturated versus saturated fatty acids present there in addition to excess of monounsaturated fatty acids (MUFA). Recent advances in nutritional immunology, awareness of low calories food and stimulating actions of phytochemicals on neuronal diseases show promise as functional foods and in the industrial sectors (Ali et al. 2009).

A constant supply of dietary nutrients is needed to support human immune systems and recovery of immune suppression triggered by inflammatory response against invasion by foreign body. Excess fat decreases the immune response and is considered to be immunosuppressive. A large variety of nutrients consisting of polyunsaturated fatty acids, glutamine, arginine, sulfur-containing amino acids and nucleotides (Mantzioris et al. 2000) and compounds like carotenoids, flavonoids, catechins, curcuminoids, tannins and fibers; fatty acids and conjugated linolenic acids are vital for healing organ failure in critical illness (Thies et al. 2001).

Due to obesity problems, there is a search for suitable fat replacements in foods without compromising the tastes. Carbohydrate substitutes are popular due to functional properties like thickening, bulking and pasting agents in various forms such as gum, pectins and cellulose that form hydrocolloids enhancing viscosity and texture (Ang 2001). Starches are good fat substitutes. Maltodextrin, dextrin, polydextrose, insulin and fibers are frequently used in place of fats (Malkki 2001). Carbohydrate and protein-based substitutes are preferred in bakery, meat, mayonnaise, cheese 
spreads, butter, and margarine. Since proteins are good emulsifying, foaming, gelling and water absorbing substances, they are preferred as fat substitutes in a variety of foods. For example, milk, egg, whey and soy proteins are processed by gelation, aggregation and cross linking to make them fat replacements (Kulozic et al. 2003). Whey lactoglobulin is modified by hot aggregation and thermal fractionation to make it a fat substitute (Orlein et al. 2006). Proteases and transglutaminases mimic fats by enzymatic modification of certain proteins (Kunst 2003). Some fatty acid esters are very good fat-based substitutes. There are two types of lipid analogs having almost zero calorie properties: (a) carbon chain fatty acids; and (b) sucrose, or some mono-saccharides to replace glycerol back bone to hold the fatty acids.

Around 4000 flavonoids exist in fruits, vegetables, nuts, cereals, legumes, spices, tea and coffee. Flavonoids are good antioxidant besides helping in chelating metal ions and forming complexes with bioactive proteins such as enzymes, especially those involved in generation of free radicals (Majzisova \& Kuchta 2001).

Carotenoids like carotene, zeaxanthin; lutein, canthaxanthin, astaxanthin and lycopene resist infections. Low density lipids (LDL) lycopene prevents oxidative damage in proteins and lipids and thus prevent atherogenesis and carcinogenesis. Curcumin is a well known anti-oxidant, anti-inflammatory and anti-tumor compound (Gao et al. 2004) besides reducing nitric oxide and is effective in colitis (Ukil et al. 2003) and allergy (Kurup \& Barrios 2008).

A large variety of vegetables are effective in chronic diseases as they minimize reactive oxygen species and inflammatory biomarkers (Athar \& Bokhari 2006). Mixed vegetable soup reduces homocysteine in blood thereby improves bioavailability of cartenoids including other nutrients (Paterson et al. 2006). Berries activate immune response by increasing the number of macrophages in blood that provides strong defense as spleen phagocytes (Chao et al. 2004).

Bioactive chemicals in apple, citrus fruit, guava and berries control disorders through antinitrosation, inhibiting DNA adducts biosynthesis and facilitating protective enzymes activity as glutathione transferase (Craig 1999). Foods containing folate, biotin, niacin, catechins and flavonoids are effective against cancer (Oommen et al. 2005). Guava leaf extract prevents diabetic complications (Wu et al. 2009).

Vitamin $\mathrm{C}$ is reactive oxygen species scavenger eliminating endothelial dysfunction (Feldman et al. 2001) besides causing secretion of nitric oxide and regulating vasodilatation responsible for diseases like cancer, diabetes, obesity, renal disorder and coronary arterial diseases. It is an antioxidant neutralizing reactive oxygen species in chronic diseases. It improves the phenomena of inflammatory endothelium dependent vasodialation (Korantzopoulos \& Galaris 2003).

Spices and nuts from clove, cumin seeds, turmeric, onion, garlic, fennel, fenugreek, nutmeg, mace and many others are rich in nutraceuticals. Garlic lowers LDL and enhances HDL, and allicin/ajoene in it inhibits nitric oxide synthase by reducing protein/mRNA and promoting vasodilatation. Strong immunemodulating characteristics of garlic enhance proliferation of T-lymphocytes and augment the response of delayed hypersensitivity. Aged garlic extract is a promising immune modifier with homeostasis balance and particularly useful in Sarcoma and lung cancer (Kyo et al. 2001). Both oil and water soluble garlic compounds reduce dementia and coronary diseases (Borek 2006) whereas garlic oil prevents blood coagulation even in diabetic patients (Ohaeri \& Adoga 2006). Garlic aqueous extract affects cell cycle and viability of hepatoma cells (De Martino et al. 2006). 
$\beta$-glucan in cereals is currently used as fat replacement (Woods \& Navder 2006). Cereal brans are antioxidant (Serpen et al. 2008). Oats are rich in $\beta$-glucans that have good water retention; gelling and hydrocolloid-forming properties appropriate for fat replacement besides cholesterol lowering (Lee et al. 2009). Their presence in yeast cell, fungi, bacteria and cereal modulate the immune system to improve body defense (Volman et al. 2008). Fibers in gums, pectins, celluloses, hemicellaloses, tannins and phytates are often used in food supplements. Mushroom glycans form polysaccharides with glucose, galactose, mannose, xylose, arabinose, fucose, ribose and glucouronic acid while conjugating with proteins or peptides show antitumor activity (Zhang et al. 2007).

\section{Date of submission: May 2012 Date of acceptance: June 2012}

\section{REFERENCES}

Ali, R, Athar, M, Abdullah, U, Abidi, SA \& Qayyum, M 2009, African Journal of Biotechnology, vol. 8, no. 6, pp. 891-898.

Ang, JF 2001, Cereal food world, vol. 46, pp. 107-111.

Athar, M \& Bokhari, TZ, 2006, J. Vegetable Sci., vol. 12, pp. 27-38.

Blumenthal et al. 2000, Herbal medicine: Expanded commission e. monographs, Integrative Medicine Communications, Boston.

Briskin, DP 2000, Plant Physiology, vol. 124, pp. 507-514.

Borek, C 2006, J. Nutr., vol. 136, no. 3, pp. $810 \mathrm{~S}-812 \mathrm{~S}$.

Cacace, JE \& Mazza, G, 2007, 'Pressurized low polarity water extraction of biologically active compounds from plant products', in Functional food ingredients and nutraceuticals processing technologies, eds Shi, Taylor \& Francis, Boca Ratan.

Chao, S, Schreuder, M, Young, G, Nakaoka, K, Moyes, L \& Oberg, C, 2004, J. Am. Nutraceut. Assoc., vol. 7, pp. 32-38.
Craig, WJ 1999, Am. J. Clin. Nutr., vol. 70, pp. 491S-499S.

De Castro, MDL \& Jimenez-Carmona, MM 2000, Trac-Trends in Analytical Chemistry, vol. 19, pp 223-228.

De Martino, A, Filomeni, G, Aquilano, K, Ciriolo MR \& Rotilio G, 2006, J. Nutr. Biochem., vol. 17, pp. 742-749.

Dionisi, F et al. 1999, J. Food Sci., vol. 64, pp. 612-615.

Eggers, R et al., 2000, Brazilian J. of Chemical Engineering, vol. 17, pp. 329-334.

Feldman, C, Anderson, R, Theron, AJ, Steel, HC, Rensburg, CEJ, Cole, PJ \& Wilson, R 2001, Eur. Respir. J., vol. 18, pp. 122-129.

Gao, X, Kuo, J, Jiang, H, Deeb, D, Liu, Y, Divine, G, Chapman, RA, Dulchavsky, SA \& Gautam, SC 2004, Biochem. Pharmacol., vol. 68, pp. 51-61.

Greenwald, CG, 1991, 'Overview of fat and cholesterol reduction technologies', in Fat and cholesterol reduced foods: technologies and strategies, Chap. 3, Advances in Applied Biotechnology Series, eds, C Haberstroh \& CE Morris, Gulf Pub. Co, The Woodlands, Texas, USA, vol. 12, pp. 21-32.

Hakuta, Y, Hayashi, H \& Arai, K 2003, Current Opinion Solid State \& Material Science, vol. 7 , pp. 341-351.

Hartono et al. 2001, Chem. Eng. Science, vol. 56, pp. 6949-6958.

Huang, KC 1999, Pharmacology of chinese herbs. CRC Press, Boca Raton, FL.

Jung, J \& Perrut, M 2001, J. Supercritical Fluids, vol. 20, pp. 179-219.

Kompella, UB \& Koushik, K 2001, Critical Reviews in therapeutic Drug Carrier Systems, vol. 18, pp. 173-199.

Korantzopoulos, P \& Galaris, D 2003, J. Clin. Basic Cardiol., vol. 6, pp. 3-6.

Kulozik, U, Tolkach, A, Bulca, S \& Hinrichs, J 2003, Int. Dairy J., vol. 13, pp. 621-630.

Kunst, T 2003, in Handbook offood enzymology, eds JR Whitaker, AG Voragen, DWS Wong, Marcel Dekker, New York, pp. 221-236.

Kurup, VP \& Barrios, CS 2008, Mole. Nutr. Food Res., vol. 52, pp. 1031-1039. 
Kyo, E, Uda, N, Kasuga, S \& Itakura, Y, 2001 J. Nutr., vol. 131, pp. 1075-1079.

Lang, QY \& Wai, CM 2001, Talanta, vol. 53, pp. 771-782.

Lebot, V, et al. 1999, Econ. Bot., vol. 53, pp. 407-418.

Lee, S, Inglett, GE, Palmquist, D \& Warner, K 2009, LWT - Food sci. technol., vol. 42, pp. 350-357.

Majzisova, G \& Kuchta, M 2001, Physiol. Res., vol. 50, pp. 529-535.

Malkki, Y 2001, Cereal Food World, vol. 46, pp. 196-199.

Mantzioris, E, Cleland, LC, Gibson, RA, Neumann, MA, Demasi, M \& James, MJ 2000, Am. J. Clin. Nutr., vol. 72, pp. 42-48.

Ohaeri, OC \& Adoga, GI 2006, Biosci. Rep., vol. 26, pp. 1-6.

Oommen, AM, Griffin, JB, Sarath, G \& Zempleni, J 2005, J. Nutr. Biochem., vol. 16, pp. 74-77.

Orlien, V, Pedersen, HB, Knudsen, C \& Skibsted, LH 2006, Milchwissenschaft., vol. 61, pp. 3-6.

Paterson, E, Gordon, MH, Niwat, C, George, TW, Parr, L, Waroonphan, S \& Lovegrove, JA 2006, J. Nutr., vol. 136, pp. 2849-2855.

Reverchon, E et al. 2000, J. Supercritical Fluids, vol. 17, pp. 239-248.

Saldaña, MDA et al. 2002, J. Supercritical Fluids, vol. 22, pp. 119-127.

Schulz, V et al. 1998, Rational phytotherapy: a physician's guide to herbal medicine, SpringerVerlag, Berlin.
Serpen, A, Gökmen, V, Pellegrini, N \& Fogliano, V 2008, J. Cereal Sci., vol. 48, pp. 816-820.

Shi, J, Kassama, LS \& Kakuda, Y 2007 , 'Supercritical fluid technology for extraction of bioactive components', in Functional food ingredients and nutraceuticals processing technologies, eds Shi John, Taylor \& Francis, Boca Ratan.

Singh, YN \& Blumenthal, M 1997, Herbalgram, vol. 39, pp. 33-55.

Thies, F, Nebe-von-Caron, G, Powell, JR, Yaqoob, P, Newsholme, EA \& Calder, PC 2001, Am. J. Clin. Nutr., vol. 73, pp. 539-548.

Ukil, A, Maity, S, Karmakar, S, Datta, N, Vedasiromoni JR \& Das, PK 2003, Br. J. Pharmacol., vol. 139, pp. 20-218.

Volman, JJ, Ramakers, JD \& Plat, J 2008, Physiol. Behavior, vol. 94, pp. 276-284.

Wink, M \& Schimmer, O 1999, 'Modes of action of defensive secondary metabolites', in Functions of plant secondary metabolites and their exploitation in biotechnology, ed M Wink, CRC Press, Boca Raton, FL, pp. 17-112.

World Health Organization 1999, Monographs on selected medicinal plants, vol. 1, World Health Organization, Geneva.

Wood, E \& Navder, KP 2006, J. Am. Diet. Assoc., vol. 106, no. 1, pp. A55.

Wu, JW, Hsieh, CL, Wang, HY \& Chen, HY 2009, Food Chem., vol. 113: pp. 78-84.

Zhang, M, Cui, SW, Cheung, PCK \& Wang, Q 2007, Trends Food Sci. Technol., vol. 18, pp. 4-19. 